\title{
On the Contribution of Adjunct Engineering Faculty to Learning Programs: Enhancing the Practice and Providing Guidance to Solving Real Problems
}

\section{Dr. Waddah Akili, Iowa State University}

Waddah Akili has been in the academic arena for over 37 years. He has held academic positions at Drexel University, Philadelphia, Penna (66-69), at King Fahd University of Petroleum \& Minerals, Dhahran, Saudi Arabia (69-87), and at the University of Qatar, Doha, Qatar (87-00). Professor Akili's major field is geotechnical engineering and materials. His research work \& experience include: characterization of arid and semi arid soils, piled foundations, pavement design \& materials, and concrete durability. His interests also include: contemporary issues of engineering education in general, and those of the Middle East and the Arab Gulf States in particular. 


\title{
On the Contribution of Adjunct Engineering Faculty to Learning Programs: Enhancing the Practice and Providing Guidance to Solving Real Problems
}

\begin{abstract}
The paper (an Evidence-based Practice paper) examines the status quo of adjunct faculty in engineering institutions and argues for the positive contributions adjuncts, with practical experience, could make by bringing their experience into the classroom. Also, in setting up linkages with industry which often leads to employment opportunities for graduates, co-op activities, and potential development of collaborative research programs. Unfortunately, adjuncts are marginalized by the academic systems in place today; and their contributions to the academic process are undervalued. Next, the paper reports on the success story of an adjunct, a practitioner with good credentials, who "teamed-up" with a "full-time" faculty, in an attempt to bring the practice to $4^{\text {th }}$ year students in a geotechnical/foundation engineering class. The success achieved in meeting course objectives, was attributed, in large measure, to proper planning and coordination that preceded course delivery. Plus, the willingness, experience and abilities of the adjunct in addressing the practice in the locale. The positive outcome of this experience has encouraged other faculty members to search for practitioners- as adjuncts- to assist in bringing the practice into the classroom, in partnership with "full-time" faculty.
\end{abstract}

\section{Introduction:}

If given the opportunity, adjunct faculty who have practiced engineering, could enrich an academic program by bringing in their practical experience and by introducing relevant applications and design venues to the classroom. The practical experience of adjunct faculty manifests itself in various ways. In particular, their familiarity with the "nuts \& bolts" of the practice, including: appropriate design and construction methods, customer needs, alternative solutions, environmental and social impact aspects of the design, as well as, their experience in decision-making, are ample reasons why their expertise would enrich students' learning and brings them (the students) closer to the realities of the workplace [1].

Employers, by and large, are generally satisfied with the basic technical preparation of today's graduates, but find them largely unaware of the vital roles that engineers play in bringing products and services from a "concept stage" to the marketplace. An important reason for this "drawback" is that faculty members, today, often lack industrial experience and/ or any other type of practical experience. This is particularly troubling when faculty members, straight out of graduate school and have absolutely no experience "under their belt," are assigned to teach practice related courses. Often, teaching design-oriented and/ or field-related subjects do require "first-hand" knowledge that instructors could only get by having taken part, or been involved in real engineering problems. Relying mainly on textbooks and/ or reference material, as the only source to teach from, is regarded by many, as an oversimplification or a deviation from reality.

This paper sheds light on the pros and cons of opening-up to off-campus practitioners, and argues for engaging properly selected adjunct faculty in the teaching-learning process, in partnership with "full-time" regular faculty members. The impetus here is three fold. First, the general belief that well-seasoned and experienced practitioners can be a tremendous resource to tap; in combination with regular "full-time" faculty- who are, in most instances, the "research- 
type," and who have not had the opportunity to practice engineering. Second, industry's prevailing perception that engineering education does not prepare graduates adequately for the practice. Therefore, from industry's perspective, the quality of education for engineering practice is seen as deficient. Third, blending practical experience in teaching design and design-related courses is repeatedly emphasized by ABET, and by other engineering organizations, such as ASEE [2,3] .Thus, directions for proper merging of professional experience with engineering science in design courses are a concern that comes up often in educational forums. How best could such "a merging scenario" be planned and implemented, depends on: faculty foresight, available resources, and the commitment- of the faculty and the administration-to the mission.

The paper reports on a success story of such a merger in a geotechnical/foundation class. The success achieved was attributed, in large measure, to the proper coordination that preceded course delivery. In this exercise, an experienced and willing practitioner was sought out to supplement the regular lectures offered in an elective course to $4^{\text {th }}$ year civil engineering students. Students' evaluations, their views, comments and overall impressions (during-and at the end of the course) have been very encouraging to say the least! The positive outcome of this experience has led other faculty members to follow the same path, i.e., by searching for practitioners as "adjunct faculty", to assist in "bringing-in" the practice into the classroom.

\section{The Pros and Cons of Adjuncts:}

There are many reasons for employing adjunct faculty. Unanticipated increase in enrollment, the startup of new programs, the need for specific expertise, and the replacement of an "on-leave" faculty, are some of the reasons that may necessitate making temporary arrangements to ensure coverage of instruction. Unfortunately, administrators and most faculty members, look upon hiring an adjunct faculty as a "stop-gap" measure. Not only that, but there are those skeptics, that are vehemently against employing adjuncts on the grounds that: i) they do not have the teaching skills, ii) are not familiar with rules and regulations that control the day to day academic operations, iii) lack organization skills, iv) do not possess the self-confidence and/ or the enthusiasm, and, v) lack familiarity and depth of insight with course material. Simultaneously, there is a growing recognition of the potential contributions that adjuncts could make in the teaching arena, provided a thorough search for "the right type" of adjuncts is carried out.

Although no firm rules or guidelines on how to search and identify candidates for an adjunct position are available at present; the most common starting point is the unsolicited applications from individuals in industry and consulting firms, seeking part-time work as adjunct faculty. The motivation often is to supplement their income. There are those that like to do it for other reasons such as: exposure to the academic environment, an interest in working with students, to gain experience in presentation and delivery of information, to take time-out from their daily schedule, or as a stepping stone into a full-time teaching position. In addition, "full-time" faculty may recommend colleagues, from outside campus, they have known through professional societies or through other domains - who may have expressed an interest in working with students. Another approach, though not widely practiced, is to advertise in specialized newsletters and magazines, spelling out in some details relevant information about: the position, desired qualifications, and the conditions of employment.

A thorough review of candidates' qualifications and experience is necessary, but may not be 
sufficient in insuring quality of instruction. Candidate's ability to deliver a lecture properly should be put to the test through his/ her presentation of a seminar attended and evaluated by faculty members and students. Presentation of a technical seminar, though stressful for some candidates, is an invaluable means for assessing candidate's teaching skills. A scheduled presentation is also an opportunity for regular faculty to meet adjunct candidates, before and after the seminar, to get to know the candidate and discuss matters of mutual interest, including potential future collaboration [1].

Some of the adjunct faculty-particularly those who are seniors in specific industries- could offer important linkages for the development of industrial affiliate programs, co-op activities, summer training opportunities, and employment opportunities for new graduates. They may also provide new ideas for senior design projects, topics for graduate theses, or render help in the establishment of collaborative research programs.

When a choice has been made and the candidate has accepted, it is important that he/ she feels welcome and be assisted in becoming familiar with his/ her new surroundings. To expedite the process, new adjuncts should sit together with their new colleagues and go over all relevant matters related to their assigned tasks, ranging from course objectives, to teaching logistics, and including prevailing classroom culture and department vision. For the new adjuncts to feel at home and become effective members of the university community, they need to understand the mission, prevailing practices, and goals; and, also, the traits of student population such as: scores, interests, capabilities, and a wide range of relevant statistics. To improve the teaching effectiveness of novice adjuncts, they need to be exposed to pedagogical training in the form of seminars/ workshops, or short courses. Many adjuncts, particularly part-timers, may resist getting any formal training on the ground that their time is limited and their primary job is offcampus, not teaching! The administration may not be able to convince all, but the fact remains that exposure to teaching principles, would have positive impact on faculty teaching skills [4].

The academic systems in place today have not been fair to adjuncts in general. The author has known of many "full-time" adjuncts that have been mistreated despite their proven records of being very good teachers. They are often marginalized by the tenure system, in the sense that their contributions to the academic process are undervalued. As pointed out by Gosink and Streveller [1]; there are ways for recognizing the contributions of adjuncts, including the following:

- Look into the feasibility and/ or the legal aspects of offering 3-5 year contracts to those who have demonstrated their abilities as good teachers.

- Accord appropriate titles, awards and citations to distinguish proven teaching skills of qualified adjuncts, on par with regular faculty members.

- Encourage new recruits to take graduate courses towards a degree or to develop new skills, including teaching skills. This is usually done on campus at no cost to the department.

- Encourage experienced instructors to teach new courses: to widen their scope, and, thus help them get out of "a rut" by developing new potentials and be of more value to the department.

- Allow those with experience to serve on various academic committees and assign them to undergraduate advising, as is the case with regular faculty.

- List those that have been in the teaching arena for over a year in catalogues and brochures. 
In summary, if care, recognition, and fair treatment are accorded to adjuncts, their morale, loyalty to the department, as well as their teaching effectiveness would improve markedly.

\section{Reporting on the Experience:}

At one of the International Universities, a course, Foundation Engineering, introduces students to the fundamental concepts and applications of foundation analysis and design, with emphasis on relevant methods and applications in the arid and semi-arid soils of the Country in contention and the Region in general. The prerequisite, Geotechnical Engineering I, exposes students to the basics of soil mechanics: from classifications of soils to consistency and the limits, on to soil water/permeability/seepage and effective stress principle, leading to compressibility and consolidation, and ending with shear strength evaluation and testing principles [5]. The author who happens to be the instructor for both courses, has always been of the opinion that certain subjects, including Foundation Engineering, should be instructed by practitioners; but, if not feasible, then practitioners should be involved in the instructional process, possibly as guest speakers. To proceed with the idea of bringing the practitioner to the classroom, a preliminary plan was drawn, and a search for an expert on the subject, commenced as soon as formal approval was secured. A formal announcement was dispatched to various companies in the Region describing the position, desired qualifications, financial compensation, and other employment-related conditions. It was also stipulated, that the appointment is initially for one year, renewable for longer periods, depending on outcome and feedback from students and faculty.

The search led to a candidate that had the desired qualifications, and was willing to accept the position, but had no prior teaching experience. However, his skills in lecturing and delivery of teaching materials were put to the test by having him present a seminar on a subject of his choice. Attendees' overall impression was positive. On that basis, he joined the department as a part-time adjunct faculty. He was particularly suited for the position because of his knowledge and familiarity with the soils and geology of the Region, and, his involvement with the practice in the locale. Being in charge of the geotechnical section in his consulting firm, facilitated getting the right kind of information and records, such as: soil data, case studies, exposure to equipment in-use, and relevant testing procedures. Most important, he was excited, eager and looking forward to bringing-in his experience to the classroom.

Initially, three different alternatives, on how to proceed with the instruction of Foundation Engineering, and in particular, the role/ contribution of the adjunct to the process, emerged. Alternative One was for the adjunct faculty to take complete charge, teach the course in its entirety, and consult with the "full-time" faculty when necessary. Alternative Two, called for apportioning teaching into two separate parts. The major part (embodying most of what is normally covered in prior semesters) would be handled by the "full-time" faculty; while the adjunct's contribution to the course, estimated at 20 to $30 \%$ of total class time, would focus on the practice-side, i.e., addressing design and construction of foundations in the locale.

Alternative Three specified a joint effort in terms of: planning and delivery of subject matter, organizing in-class and out of class activities, and in testing and evaluation. It was understood that the adoption of Alternative Three meant that both instructors would be present in the class room, at the same time, and actively involved in the instructional process: delivering the material in a coordinated manner, engaging students through questions \& answers, or open discussion. 
After an exhaustive and thorough search, Alternative Three appeared to be the preferred choice for both instructors, who were willing to "give it a try" and pledged to put in the extra effort that may be required to guarantee success. In the sections that follow, we examine relevant aspects that pertain to planning the course, conducting the course, and focus, particularly, on the role of the adjunct in this endeavor.

1) Course planning: To begin with, a course plan agreed upon by both instructors was drawn up embodying instructors' vision of what needs to be covered in the time allotted. The plan had four elements: a set of instructional objectives, a course syllabus, a fair and equitable testing and grading guidelines, and a "back up" scenario for students that need more attention.

1) Instructional Objectives: This aspect was a construct of: (i) the knowledge and skills that will be conveyed ; (ii) what students must be able to do when finishing the course successfully; and, (iii) what constitute an acceptable performance. Thus, preparing the objectives helped clarify purposes and goals, allowing the instructors to identify important material, delete extraneous content, and plan course activities in an efficient way.

2) Course Syllabus: The syllabus, made up of ten interconnected parts, described course content, communicated goals, and included instructional objectives that guided course delivery. It also contained grading policy, provided information about selected textbook and reference material, and addressed other course logistics. Table 1 presents an "abridged" course outline with pertinent details. Time-wise, the course outline was apportioned and streamlined in order to insure that actual delivery was held within the allotted time: i.e., three contact hours per week, for a total of sixteen weeks, plus an additional hour for questions and answers and/ or to supplement the regular lecture, for those that need it. To enrich the "practice-side" of the course, plans and provisions were made for: presentation of three selected case histories based on work done in the locale, and believed to be of relevance to course material; plus three pre-arranged field trips to sites nearby, to expose students to: (i) exploration and field testing equipment and methods in use, as well as, to (ii) field data acquisition systems deployed in the area. Table 2 is a tally of the cases presented. Table 3 describes trips made during the course cycle referred to in this article. 3) Testing and Grading: Unlike prevailing norms of testing and grading, the guidelines from which instructors could measure students' accomplishments allowed for group collaboration in addition to individual performance. It was made clear, at the outset, that a course grade would be arrived at based on a combination of the following:

- Homework and joint projects submitted by the group,

- One mid-term exam and a final,

- A minimum of two-page commentary on each of the case histories presented in class,

- A brief group report for each of the field trips.

Instructors would also look at class participation through questions and answers, attendance, and collaboration within the group. To encourage teamwork, the instructors would do their at most to foster student cooperation, diminish competition, and insist that students compete with a "set standard" and not compete with each other. An additional bonus that helps those that may not do well on the mid-term is to be given the opportunity to "resurrect" those points on the final. The idea is as follows: points a student misses on the mid-term are logged on the record as "unearned points" in such a way that the corresponding section of the final is increased in value by the same number of points $[6,7]$. For students, this plan translates into the possibility that, however poorly they perform on the mid-term, they do have the opportunity to raise their grade in the course. 


\begin{tabular}{|c|c|c|c|}
\hline Part & Title & Details & $\begin{array}{c}\text { Time } \\
\text { Allocated }\end{array}$ \\
\hline $\mathbf{I}$ & Review & $\begin{array}{l}\text { Index Properties } \\
\text { Stresses and Strains }\end{array}$ & One Week \\
\hline II & Regional Geology \& Soils & $\begin{array}{l}\text { Desert Soils, Saline Soils } \\
\text { Cemented Soils }\end{array}$ & One Week \\
\hline III & $\begin{array}{l}\text { Compressibility, Consolidation, and } \\
\text { Settlement }\end{array}$ & $\begin{array}{l}\text { Theory, Relevant Tests and } \\
\text { Techniques }\end{array}$ & One Week \\
\hline IV & $\begin{array}{l}\text { Bearing Capacity Theory and } \\
\text { Calculations }\end{array}$ & $\begin{array}{l}\text { Appropriate Formulae, Charts and } \\
\text { Procedures }\end{array}$ & Two Weeks \\
\hline $\mathbf{V}$ & $\begin{array}{l}\text { Shallow Foundations } \\
\text { (Footings and Mats) }\end{array}$ & Bearing Capacity Considerations & Two Weeks \\
\hline VI & $\begin{array}{l}\text { Shallow Foundations } \\
\text { (Footings and Mats) }\end{array}$ & Settlement Considerations & Two Weeks \\
\hline VII & $\begin{array}{l}\text { Deep Foundations } \\
\text { (Piles, Shafts, and Piers) }\end{array}$ & Bearing Capacity Considerations & Two Weeks \\
\hline VIII & $\begin{array}{l}\text { Deep Foundations } \\
\text { (Piles, Shafts, and Piers) }\end{array}$ & Settlement Considerations & Two Weeks \\
\hline IX & Case Histories & $\begin{array}{l}\text { Three Cases Depicting Regional } \\
\text { Behavior }\end{array}$ & One Week \\
\hline $\mathbf{X}$ & Field Trips & Three Pre-Selected Sites & One Week \\
\hline
\end{tabular}

Table 1. An abridged course outline of Foundation Engineering.

\begin{tabular}{|l|l|l|}
\hline \multicolumn{1}{|c|}{ Designation } & \multicolumn{1}{c|}{ Details } \\
\hline $\mathbf{1}$ & $\begin{array}{l}\text { The Settlement of the } \\
\text { Two Hundred Bed } \\
\text { Hospital }\end{array}$ & $\begin{array}{l}\text { Exposing students to probable cause of excessive } \\
\text { settlement of footings over saline soils and the remedial } \\
\text { measures that were implemented }\end{array}$ \\
\hline $\mathbf{3}$ & $\begin{array}{l}\text { Driven Pile Foundations } \\
\text { in Calcareous Sand }\end{array}$ & $\begin{array}{l}\text { Exposing students to design and installation of piled } \\
\text { foundation for a 20 story building in calcareous sand }\end{array}$ \\
\hline & $\begin{array}{l}\text { Building Foundation } \\
\text { Over Expansive Soil }\end{array}$ & $\begin{array}{l}\text { Exposing students to the use of foundation piers with a } \\
\text { suspended floor slab over an } \text { expansive soil }\end{array}$ \\
\hline
\end{tabular}

Table 2. Three case histories typical of geotechnical/foundation problems and conditions in the Region (selected and presented by the adjunct faculty) 


\begin{tabular}{|c|c|c|}
\hline Site No. & Trip Reference & Details \\
\hline 1 & Subsurface Exploration & $\begin{array}{l}\text { - } \text { Observing borehole drilling operations } \\
\text { - } \quad \text { Soil sampling, Split-Spoon Sampling } \\
\text { - } \quad \text { Ose of: Thin Wall Tubes, Piston Sampler, Rock Coring } \\
\text { - Observations of water table fluctuations } \\
\text { - } \quad \text { Preparation of boring logs }\end{array}$ \\
\hline 2 & $\begin{array}{l}\text { Plate Load Test \& } \\
\text { Settlement Monitoring }\end{array}$ & $\begin{array}{l}\text { - Observing a Plate Load Test in progress } \\
\text { - Monitoring foundation settlement on sand }\end{array}$ \\
\hline 3 & Pile Driving in Sand & - Observing pipe piles driven in sand \\
\hline
\end{tabular}

Table 3. The three field trips intended to expose students to relevant geotechnical/foundation operations (selected and conducted by the adjunct faculty).

4) A "Back up" Plan to Assist Slow Learners: There are always students that fall behind, or do not get it the first time; and, therefore, require more attention and/ or assistance to try to catch up. The instructors did find out, soon after the course had started, who amongst the group required additional help to cope with the material and raise his/ her standard to the desired level. The devised plan (Backup Plan) was a combination of the following: (i) allocation of additional time to reinforce information given during regular class time; (ii) simplification of the harder concepts using different techniques and/ or applications, and; (iii) to instill a sense of community amongst the students, i.e., students themselves would help each other in coping with the material and/ or overcoming difficulties encountered. By the end of the course, almost $15 \%$ of the students had benefited from the "Back up" plan, and were appreciative of the extra effort and care shown by the instructors and members of their own group.

2) Course Delivery: Getting off to a good start proved to be vital to instructors and students alike. The first two sessions were ideal opportunity to be clear about expectations and to impress on the students that the course is well-planned and organized in such a way that having two instructors is positive and very beneficial to the students long-range. It was the time for the two instructors: to share their views and expectations for the course, to describe the overall goals of the course, to explain the role of each of the two instructors in the course; and in particular, how the two instructors plan to "intertwine" the course material, letting the practice and its ramifications supplement the theory, the principles, and the descriptive portions.

Typically in the 50 minute lecture period, one of the two instructors would start the session by: presenting the topic on hand, disseminating the prepared material (aided by the overhead projector), followed by a pause for a few minutes. During the pause, the students would raise questions that are normally answered by either one of the two instructors; then the lecture is resumed and brought to a terminal point for the day followed by either: an open discussion, a demonstration, an elaboration and/ or comments made by the instructor, who is not the lead instructor for that day or that week. Each class period was designed with the goals of: (i) improving students understanding of the new concepts in a systematic manner, and resurrecting 
some of the knowledge they had in prerequisites; (ii) having students apply the new learned concepts, and develop in them the ability to "globalize" by looking at the problem on-hand from different perspectives; and, (iii) help stimulate interaction by encouraging students to ask questions during the pause periods, and help them develop the self-confidence needed to overcome language difficulties resulting from the fact that the language of instruction is English, while students' native language is an entirely different language!

Another way to establish a positive classroom demeanor was: to adhere to the scheduled start and stop time of the class; to deliver the material at a reasonable pace; to assign "help" sessions when needed; to avoid reading "verbatim" from the textbook or other references; to provide copies of relevant materials, in order to help students reduce having to take extensive notes during the class period; and, to make use of a website to deliver appropriate course-related material, as needed. Also, the two instructors were generous with their time during office hours, and were responsive to students' requests, and open to suggestions and new ideas. To further promote a successful classroom environment, the instructors utilized positive, optimistic, and success-oriented teaching. They were trying to harness a spirit of cooperation and understanding and to foster a desire amongst students to do their "level best!", and that effort and time spent by the students is going to pay off at the end. Despite the positive spirit that prevailed, the instructors were apprehensive and concerned, i.e., would they be able to meet stated objectives and bring the course to a successful conclusion? A list of their concerns included the following:

- Are the students being overloaded? And, is the material being delivered at the right pace?

- In terms of time and effort: the course should probably be worth four credit hours rather than three? Possibly, a recitation and/ or a lab session need to be added?

- From students' perspective, having two instructors in the classroom, at the same time, is not common and may be confusing to some students. ? Do students need to have rapport with both instructors? Are instructors' expectations realistic? Will the students respond positively to this novel approach of course delivery?

- Are instructional activities properly designed to meet the challenge?

Towards the latter part of the course, and because of class time limitations, the instructors had to eliminate some of the topics that had been scheduled initially. It was later realized that there was more material in the initial syllabus than could be effectively handled. Also, to promote effective learning, within the context of varied learning styles [8], it is advisable to form groups within the class and to monitor the performance of the groups to insure that each and every group is a "working unit," and members of the group do get along well, help each other and learn from one another. The instructors grouped the students, devised activities and tasks that brought the students closer together, and made sure that joint tasks were consistent with course objectives. Therefore, an attempt to create an active learning environment was pursued in this experiment, despite the fact that traditional teaching methods were dominant and practiced on a wide scale. Active learning implies class participation, i.e., the students, the instructors, and the teaching material are intertwined through preconceived and organized learning/ teaching activities [4]. Research has shown that what students tend to remember is highly correlated with their level of involvement $[9,10]$. Edgar Dale's cone of learning shows that students remember about $20 \%$ of what they hear, $30 \%$ of what they see; but tend to remember up to $90 \%$ of what they actively participate in, such as: discussions, questions and answers, problem-solving, and hands-on activities [11] . This is to say: the higher the level of student involvement, the greater is his/ her 
comprehension and the higher is his/ her retention. Indicators have shown that an active learning environment has a positive impact on student's personality. It tends to boast self-confidence, improves communication skills, and makes the student a better team member.

For cooperative learning experience -which is part of active learning- to be successful, it is imperative that the following be integrated into the class activity: [9, 12, 13, and 14].

- Interdependence-Students should perceive that they need each other to complete the planned activity;

- Interaction- Students should work together in planning, executing, and arriving at conclusions. They should share the work load equitably and share the credit;

- Accountability- Students should be accountable individually \& as a group. Keeping track of knowledge gained by the individual (through the group) should not be overlooked;

- Sharing known skills- Students who possess certain knowledge or skills (computer skills, laboratory skills, data analysis and reduction skills, writing skills, presentation skills, etc.) should be willing to pass it on, and/ or share it with their group members;

- Collaborative skills- Groups cannot function effectively if members do not have (be willing to learn) or use some needed social skills. Such as: leadership, decision-making, trust building, and conflict management;

- Monitoring progress- Groups need to discuss amongst themselves whether they are achieving their set goals. They need also to prioritize the scheduled activities, introduce changes when needed, and solicit advice and assistance with the consent of the instructor. Success in implementing active learning, including cooperative learning, is attributable, in large measure, to: proper planning, dedication and care shown by the instructors, as well as their abilities and foresights. Experience is definitely a major factor.

A proper start for instructors wanting to try active learning is to step into it gradually, seek continuous feedback from students who are directly involved, and consult with experienced colleagues who can offer constructive comments and advice [4, 7].

3) The Role of the Adjunct Faculty: From the previous sections, it is reasonable to infer that Foundation Engineering, in general, went rather well and was almost on target. In retrospect, proper planning that preceded course delivery had a lot to do with the success achieved. In all fairness, adjunct's eagerness, desire, commitments, and efforts were instrumental in meeting set goals, and declared objectives, i.e., "bring the practice into the classroom". On the planning side, the adjunct was able to generate the material (design procedures in use, relevant construction issues, prevalent soil conditions, lessons learned, typical foundation behavior and potential problems in the locale, statistics, examples, etc.). He was also able to sort it out, stream line it, and diffuse it within the general course outline so that it supplements the topics as specified in the course chronology. His selections of case histories were: relevant, derived from the locale, and addressed timely issues. He and his teammates at work were the proponents of the selected cases. They were responsible for data acquisition, engineering analysis, the write-up, and the final recommendations. The three selected field trips were also based on adjunct's recommendation, who prepared a write-up for each, explaining what would be observed, and how do field observations relate to the specifics in the syllabus.

On the Delivery side, the adjunct was always on time, present in class with the "full-time" faculty the entire semester, ready to contribute and/ or express his views at the appropriate time. 
He made good use of his "lap top", and often resorted to handouts to reduce students' notetaking during the lecture. When his turn came to deliver his part, he was courteous, considerate, and spoke clearly. His main contribution in every session was to supplement the subject matter with relevant examples derived from the Region, focusing primarily on the "practice", or the practical side of the topic on hand. For example, when settlements of shallow foundations was the theme under consideration; he showed: settlement plates being installed and fully operational, an example of the discrepancy between measured and calculated settlements, guidelines for tolerable settlement based on local building code, and presented allowable bearing pressures based on settlement consideration. He, often, presented valid points and commented on the specifics of the day during the pause periods. He led the discussion, and answered questions even when improperly phrased! The three case histories he chose to present were very relevant, and well received. He was extremely helpful during office hours, and the rapport he initiated with students during the first week, he was able to sustain throughout the semester. His contributions to the experience during the aforementioned semester can be highlighted as follows:

- His foresight, effort, and abilities, as a practicing engineer, did enrich the course, made it more relevant, and brought "real" problems into the class room,

- Drawing on his experience as a geotechnical engineer, provided students with firsthand information about local soils and their potential behavior under foundations,

- His positive ways of responding to questions, engaging students, and encouraging them to come forward with their views and comments, promoted confidence and community amongst the students,

- The presence of the adjunct faculty in class, side by side with the "full-time" faculty, broke the monotony experienced in traditional settings, and was instrumental in creating a class room environment that resembled a professional engineering forum.

The "full-time" faculty member (at that time), was lucky to have had the adjunct by his side. He (the "full-time" faculty) gained a lot from the experience. Once the precedence has been set, other faculty members in the Department wanted to follow suit, and began their search for the right type of practitioners, to enrich the academic process by bringing the practice into the class room. After Foundation Engineering was over, and the final course grade was out, a "questionnaire" was sent to those who enrolled in the class seeking their opinions, evaluations, and any comment(s) they may wish to offer. Twenty six out of a total of 30 students returned the "questionnaire" on time! The opinions expressed and comments made were, by and large, positive to say the least. After regrouping, and rephrasing to correct the English language; the comments offered by the ex- students, could be summarized as follows:

- The adjunct was easy to approach every time and everywhere, and was always helpful,

- His input into the course has dramatically improved students' understanding of the material, enlivened the experience, and made the course more meaningful,

- Many students felt that the adjunct faculty was eminently qualified to teach Foundation Engineering by himself, should the need arise. On the other hand, a considerable number of the ex-students approved of the arrangement, i.e., having the two instructors in the classroom; and many argued that Foundation Engineering could not have been delivered as effectively, had it not been for the two instructors working 
harmoniously together in planning and delivery of the course material,

- Some students expressed their desire to see similar arrangement be implemented in other Civil Engineering courses; particularly in design and construction type courses,

- The field trips, planned and conducted by the adjunct, were described as: very useful, particularly in developing an awareness of how soil exploration work is performed in the locale. Also, their comments on the value and benefits derived from the Plate Load test and the settlement monitoring site were equally positive.

The experience reported on here was repeated several times; and a number of minor changes, mostly in sequencing teaching material, were since introduced. The experience has gained momentum, and has since been applied to other engineering courses in the same institution.

\section{Summary and Concluding Remarks:}

Properly selected adjunct faculty can enrich an engineering program by bringing in their practical experience, and by introducing relevant field applications to the classroom. Adjunct faculty can also provide important linkages for developing joint programs between industry and academic departments, and, could trigger employment opportunities for graduates. Nevertheless, the position of an adjunct faculty, in most colleges, is tenuous, and subject to change in enrollments. They do suffer from: negative administration and faculty perception, limited connectivity with mainstream issues, and, often, marginalized by the tenure systems that prevail today. Their presence on campus is considered as temporary, or until replaced by a "full-time" faculty member. The current practices of hiring adjunct faculty, their "diminished role" as academics, and the difficulties that most face, must change! A change towards: improving their image, recognizing their rights, and acknowledging their contributions, need to permeate in the academic circles, in order to correct misconceptions that have persisted too long. If treated fairly and given the opportunity, the adjuncts would enhance the teaching/learning process; and, do what we, the "full-time" faculty, are not able to do, i.e., bring the practice into the classroom! Another arena for the adjunct, who possesses a proven record of practical experience in a specific area, is to "team-up" with the "full-time" faculty, to bring in the practical side of the subject into the classroom. This means that two faculty members (the "full-time" faculty and the adjunct) would share in teaching the class. There are various possibilities on how to "intertwine" the teaching material, and merge the teaching activities. In all likelihood, the main "run of the mill" instructional activities, are usually "put across" by the full-timer, while those intended to shed light on the practice, are normally handled by the adjunct, who is most likely, a practitioner.

This paper reports on a success story of such a merger in a geotechnical/foundation engineering class. The success achieved was attributed, in large measure, to the proper coordination that preceded course delivery. In this exercise, an experienced and willing practitioner was sought out to supplement the regular lectures offered in an elective course to $4^{\text {th }}$ year civil engineering students. In addition to the practice-related activities brought into the lecture hall; case histories were also introduced by the practitioner, as well as pre-selected field trips, focusing on soil exploration and other relevant monitoring and testing procedures. Students' evaluations, their views, comments, and overall impressions (during-and at the end of the course) have been very encouraging to say the least! The positive outcome of this experience has lead other faculty members to follow the same path, i.e., by searching for practitioners as "adjunct faculty"- to assist in bringing-in the practice into the classroom 


\section{References:}

1. Gosink, J.P. \& Streveller, R.A. (2000), "Bringing Adjunct Engineering Faculty into the Learning Community." Journal of Engineering Education, Vol.89, no.1, pp.47-51, Jan.2000.

2. Dym, C.L., Agogino, A.M., Eris, O., Frey, D.D., and Leifer, L.J., "Engineering Design Thinking, Teaching, and Learning," Journal of Engineering Education, Vol.94, no.1, 2005, Jan. pp.103-120.

3. Hazelrigg, G.A., "Rethinking the Curriculum: Is Today’s Engineering Education Irrelevant, Incomplete, and Incorrect?" Prism, ASEE, Wash. D.C., 1994.

4. Akili, W., "On Implementation of Classroom-Based Pedagogies of Engagement: Relevant Measures and General Outcomes," ASEE 2014 Annual Conf., (Session T125), Indianapolis, Ind., June 2014.

5. Das, B.M., Fundamentals of Geotechnical Engineering, (2 $2^{\text {nd }}$ ed.), PWS Publishing Company, Boston MA., 2002.

6. Tobias, S., They're Not Dumb, They're Different: Stalking the Second Tier. Long Branch, NJ: Science News Books, 1994.

7. Akili, W., "Improving the Classroom Environment: With a Focus on the Arab Gulf States," 2004 ACEE Annual Conf., (Session 3560), Salt Lake City, Utah, 2004.

8. Dunn, R., "Understanding the Dunn and Dunn Learning Styles Model and the Need for Individual Diagnosis and Prescription," 1990, Reading, Writing and Learning Disabilities Vol. 6, pp. 223-247.

9. Johnson, D.W., Johnson, R.T. \& Smith, K.A., “Active Learning Cooperation in the College Classroom,” Edina, MN: Interaction Book Company, 1991.

10. Fairhurst, A.M., \& Fairhurst, L.L.), “Effective Teaching, Effective Learning. ”, Palo Alto, CA: Davies-black Publishing, 1995.

11. Dale, E., “Audiovisual Methods in Teaching,” (3rd ed.), New York: Dryden Press, 1996.

12. Wankat, P.H., "Reflective Analysis of Student Learning in a Sophomore Engineering Course," Journal of Engineering Education, Vol.88, no.2, 1999, pp.195 -203.

13. Finelli, C., Klinger, A., \& Budny, D.D. (2001), "Strategies for Improving the Classroom Environment," Journal of Engineering Education, Vol 90, no.4, 2001, pp. 491-497.

14. Smith, K.A., Sheppard, A.D., Johnson, D.W. \& Johnson, R.T. (2005), "Pedagogies of Engagement: ClassroomBased Practices," Journal of Engineering Education, Vol. 94, no.1, 2005, pp. 87-101. 